\title{
EDUCAÇÃO FÍSICA, FUTEBOL E GÊNERO: UMA PROPOSTA DE ENSINO A PARTIR DAS RELAÇÕES DE PODER
}

\author{
Hudson Fabricius Peres Nunes \\ Universidade Estadual Paulista, São Paulo, Rio Claro, Brasil. \\ Thiago Farias da Fonseca Pimenta \\ Universidade Estadual Paulista, São Paulo, Rio Claro, Brasil. \\ Juliana Cesana \\ Centro Universitário da Fundação Educacional de Barretos, São Paulo, Barretos, Brasil. \\ Alexandre Janotta Drigo \\ Universidade Estadual Paulista, São Paulo, Rio Claro, Brasil.
}

\begin{abstract}
Resumo
Este estudo objetivou observar a configuração social e as relações de poder entre os gêneros a partir da experimentação e avaliação do futebol como proposta de ensino, nas turmas dos 4으 e 5은 anos do ensino fundamental, embasadas no referencial teórico de Norbert Elias. Utilizou-se da pesquisa-ação e da técnica de análise de conteúdo como procedimentos metodológicos para analisar as informações. Os resultados revelaram que o desinteresse sobre o futebol está associado à falta de habilidade motora, aos aspectos históricos e culturais. Conclui-se que as reflexões de conceitos como configuração e relações de poder utilizadas na proposta de ensino possibilitaram evidenciar alterações profícuas nas relações de gênero
\end{abstract}

Palavras chave: Relações de gênero. Valores sociais. Futebol.

\section{Introdução}

Este estudo surgiu do embate que o futebol ${ }^{1}$ provoca entre meninos e meninas nas turmas dos 4ㅇ e 5 anos do ensino fundamental. No contexto investigado, nas aulas de educação física escolar que possibilitavam a escolha das atividades preferidas, observouse que o futebol é uma das práticas corporais que mais despertava interesse entre os meninos, enquanto as meninas preferiam brincar de elástico, pular corda e dançar em outros espaços adjacentes. Durante os intervalos, também se observou que essas práticas eram recorrentes.

A oposição de interesses entre os gêneros suscitou algumas reflexões e fez emergir os seguintes questionamentos: Por que os meninos rejeitam a participação das meninas? Por que as meninas aceitam essa condição? Como as aulas de educação física esco-

- O presente trabalho não contou com apoio financeiro de nenhuma natureza para a sua realização.

1 O termo futebol está relacionado a atividades e jogos derivados do futebol, praticados na quadra ou em áreas adjacentes.

Pensar a Prática, Goiânia, v. 17, n. 4, out./dez. 2014 
lar podem contribuir para modificar estruturas de pensamento hegemônicas no que se refere a apropriação do futebol relacionadas às questões de gênero?

$\mathrm{Na}$ perspectiva de apresentar possibilidades críticas e reflexivas que auxiliem a prática pedagógica, este estudo tem como objetivo observar a configuração social e as relações de poder entre os gêneros na educação física escolar, a partir da experimentação e avaliação do futebol como estratégia e conteúdo de ensino, no âmbito das turmas dos 4ํㅜ e $5^{\circ}$ anos do ensino fundamental, embasadas nos estudos de gênero e na reflexão de alguns conceitos do referencial teórico de Norbert Elias (2000; 2008).

Nesse contexto, a questão fundamental da investigação está norteada pelo desafio de encontrar caminhos que alterem a configuração social e as relações de poder entre os gêneros, por meio de estratégias de ensino que enfatizem os valores sociais ${ }^{2}$ e possibilitem utilizar o futebol como meio de atingi-los, tornando a prática do futebol menos desigual.

\section{A educação física e os estudos de gênero}

Os estudos de gênero na educação física brasileira são influenciados por duas correntes predominantes: a marxista, que investiga as desigualdades sociais relacionadas a hierarquias de submissão e dominação; e a culturalista, influenciada por Michel Foucault, que investiga a diversidade cultural e as múltiplas identidades (LUZ JÚNIOR, 2003).

A partir da virada do século XX, os estudos de gênero na educação física começaram a se alinhar com a corrente pós-estruturalista, influenciada por autoras como Joan Scott, Judith Butler e Guacira Louro (DEVIDE et al., 2011).

Nos estudos pós-estruturalistas, compreende-se que gênero não é determinado por fatores econômicos: as construções de gênero são diversas e plurais, fazem parte das identidades das pessoas e transcendem os papéis que homens e mulheres devem desempenhar na sociedade. A construção de gênero é situada historicamente e depende dos valores com que determinada sociedade se identifica e se relaciona (relações de poder - política/ideológica), e o modo pelo qual essa sociedade produz ou reproduz conhecimento/saber/cultura (BUTLER, 2003; LOURO, 1997; 2004; SCOTT, 1995).

Entre as investigações de gênero realizadas pela educação física, encontram-se na literatura as seguintes temáticas: metodologia de ensino na educação física escolar e coeducação (ABREU, 1992; ALTMANN, 2002; ANDRADE; DEVIDE, 2006; FARIA JR.,1995; SARAIVA, 1999; SOUSA; ALTMANN, 1999; SOUZA JÚNIOR; DARIDO, 2003); mecanismos de inclusão, exclusão e autoexclusão (SOUSA; ALTMANN, 1999); inserção feminina no desporto (DARIDO, 2002; GOELLNER, 2003; 2004; 2005; GOMES et al., 2008); mídia esportiva e representações de gênero (DEVIDE, 2008; KNIJINK; SOUZA, 2004; ROMERO, 2004; 2008); identidades de gênero e práticas corporais (SAYÃO, 2002; PEREIRA, 2008).

\footnotetext{
${ }^{2} \mathrm{O}$ termo corresponde ao conjunto de valores humanos (valores morais, éticos e educativos) construídos coletivamente. Têm-se como exemplo: solidariedade, respeito, responsabilidade, cooperação, participação, tolerância, inclusão, equivalência de direitos e democracia.
}

Pensar a Prática, Goiânia, v. 17, n. 4, out./dez. 2014 


\section{Encaminhamento metodológico}

A natureza qualitativa da pesquisa e os objetivos elencados necessitaram de uma metodologia descritiva e interpretativa, que possibilitasse o diálogo com os fundamentos teóricos de uma educação física escolar crítica e comprometida com a ressignificação social dos valores futebolísticos e humanos. Como propõe L. Stenhouse (1975), este estudo identifica-se com a corrente anglo-saxônica, a da pesquisa-ação voltada ao campo educacional. Sendo assim, tais necessidades levaram a eleger, como encaminhamento metodológico, a pesquisa-ação, amparada nas proposições de Thiollent (1986), Elliott (1990, 1993) e André (1995).

Thiollent (1986, p. 14) define a pesquisa-ação como:

[...] um tipo de pesquisa social com base empírica que é concebida e realizada em estreita associação com uma ação ou com a resolução de um problema coletivo e no qual os pesquisadores e os participantes representativos da situação ou do problema estão envolvidos de modo cooperativo ou participativo.

Elliott (1990) define a pesquisa-ação como uma atividade prática, investigativa e reflexiva empreendida por grupos humanos, com o objetivo de modificar as circunstâncias sociais a partir de valores compartilhados. Para Elliott (1993), a pesquisa e a prática não podem estar separadas, o que significa que é por meio das práticas que se elaboram e comprovam as teorias, e que a produção teórica é derivada da tentativa de mudar as práticas e de construir hipóteses a comprovar.

Nesse sentido, o propósito da pesquisa-ação é a mudança de atitudes e comportamentos dos envolvidos, sendo necessário, previamente, investigar as relações sociais do contexto a ser estudado. Não é incomum esse tipo de pesquisa receber o nome de intervenção; atualmente, apesar de possuir várias correntes, todas elas abrangem um plano de ação baseado em objetivos, acompanhados de controle e ação planejada da descrição simultânea do processo (ANDRÉ, 1995).

O desenvolvimento desta investigação é semelhante ao estudo realizado por Betti (2006, p. 102), que considera a pesquisa-ação "não como uma intervenção da prática pedagógica, palavra que carrega conotação autoritária, mas como interlocução, em duplo sentido: do pesquisador com os professores/as, e destes com suas práticas".

Como sugerido no estudo realizado por Bracht et al. (2002, p. 11), entende-se que a pesquisa-ação indica um caminho mais efetivo pelo fato: "a) de vincular o conhecimento da realidade da própria prática com a ação; b) dos sujeitos, que na pesquisa "tradicional" participam meramente como informantes, aqui também atuam como sujeitos pesquisadores da sua prática".

Como técnica de pesquisa, optou-se pela análise do conteúdo descrita por Bardin (1977). Para interpretar as informações, necessitou-se analisar os Registros das Avaliações sobre as expectativas de aprendizagens coletadas pelo professor/pesquisador das turmas envolvidas. Segundo Bardin (1977), a análise do conteúdo é um conjunto de técnicas que analisa qualquer tipo de comunicação que emita significações de um emissor para um receptor. Durante a análise, buscou-se aquilo que está por trás das palavras regis- 
tradas ou ditas pelas crianças e registradas pelo professor/pesquisador. O propósito da análise é classificar as informações em unidades textuais mediante a organização, codificação, categorização e inferência.

A estruturação analítica, interpretativa, descritiva e reflexiva do estudo fundamentou-se no referencial teórico de Norbert Elias (2000; 2008) sobre os conceitos de configuração e relações de poder, desenvolvidas em três etapas:

a) Análise interpretativa e descritiva da avaliação diagnóstica dos aspectos que influenciam o embate sobre o futebol entre os gêneros no contexto escolar.

b) Análise reflexiva e descritiva da compreensão do referencial teórico de Norbert Elias à proposta de ensino.

c) Análise reflexiva, interpretativa e descritiva da avaliação processual da configuração social e das relações de poder entre os gêneros, após a proposta de ensino.

\section{Procedimentos}

Participaram desta pesquisa quatro pesquisadores e seis turmas do ensino fundamental de uma escola pública do município de Cajamar (SP), sendo três turmas do 4aa ano e três do 5o ano. A pesquisa envolveu, ao todo, 159 crianças: 83 meninas e 76 meninos.

Ao longo de cinco meses, realizaram-se dez reuniões de trabalho coletivo para apresentar os resultados e refletir as sínteses conclusivas, através das observações das relações entre os gêneros, anotadas pelo professor/pesquisador em um Roteiro de Avaliações das expectativas de aprendizagens das atividades propostas nas aulas de educação física. O propósito das reuniões era dialogar sobre a continuidade e/ou o replanejamento das próximas aulas. Nesse período, necessitou-se aproximadamente de vinte aulas para cada turma.

A proposta de ensino priorizou estratégias que proporcionassem às crianças mudanças da zona de conforto e das posições previamente estabelecidas. As atividades basearam-se nos $\mathrm{PCNs}^{3}$, na equivalência de direitos, na troca de posições/funções e na reflexão atitudinal.

\section{Aspectos que influenciam o embate sobre o futebol entre os gêneros no contexto es- colar}

Em seu estudo, Sayão (2002) destaca que as crianças se espelham no mundo adulto, porém, não de forma mecânica. Além disso, ela descreve sobre a necessidade de integrar meninos e meninas em todos os espaços educativos desde a infância, a partir de uma política educacional voltada à igualdade social e à convivência solidária. Nessa direção, a análise dos motivos de interesse ou desinteresse (aceitação ou rejeição) das crianças em participar de aulas sobre o futebol confirmaram as informações encontradas na literatura, e estão associadas aos aspectos históricos e culturais.

\footnotetext{
${ }^{3}$ Parâmetros Curriculares Nacionais (BRASIL, 1998): conteúdos conceituais caracterizam-se por uma abordagem dos fatos; conteúdos procedimentais ligados ao fazer; conteúdos atitudinais relacionado a normas, valores e atitudes.
} 
Para entender a realidade investigada, a próxima tabela apresenta a análise inicial da configuração social do grupo estudado.

Tabela 1. Avaliação diagnóstica

\begin{tabular}{ccccc}
\hline Temas & Categoria & $\mathbf{N}^{*}$ & $\%$ & Unidades de codificação \\
\hline Interesse em participar das & meninos & 72 & 95 & Para: competir; brincar \\
aulas de futebol & meninas & 8 & 10 & Porque: é um esporte masculino; as \\
Desinteresse em participar & meninos & 4 & 5 & Pon \\
das aulas de futebol & meninas & 75 & 90 & meninas são inábeis; é agressivo
\end{tabular}

*Número total: 76 meninos e 83 meninas

Ao analisar as informações ficou evidente que por trás das unidades textuais há uma forte influência da reprodução equivocada dos adultos embutida no imaginário social e cultural de ambos os gêneros. Desse modo, a transmissão de valores sociais equivocados interfere negativamente nas relações de gênero e podem ocasionar o desinteresse e a vergonha entre as meninas, e a reprodução machista e preconceituosa entre os meninos.

Nos estudos de Sousa e Altmann (1999, p. 56), as meninas "não são excluídas apenas por questões de gênero, o critério de exclusão não é exatamente o fato de serem mulheres, mas por serem consideradas mais frágeis e menos habilidosas que seus colegas". De forma semelhante, verificou-se que a rejeição em participar de aulas sobre o futebol também está associada à falta de estímulo, à inabilidade motora e ao não entendimento da estrutura de jogo. Em outras palavras, a aceitação entre as crianças não está unicamente na diferença de gênero, mas, primeiramente, se a criança consegue jogar com certa destreza e, em segundo plano, se ela é aceita pelo grupo e entende as regras do jogo.

Assim, Sayão (2002) entende que os(as) educadores(as) em suas práticas pedagógicas devem agir no sentido de diminuir hierarquias e estereótipos impostos socialmente, a fim de contribuir na construção da identidade de gêneros tendo em vista a sua pluralidade.

A favor da inclusão, os PCNs (BRASIL, 1998, p. 42) de Educação Física descrevem que:

As aulas mistas de Educação Física podem dar oportunidades para que meninos e meninas convivam, observem-se, descubram-se e possam aprender a ser tolerantes, a não discriminar e a compreender as diferenças, de forma a não reproduzir, de forma estereotipada, relações sociais autoritárias.

Para evitar a intolerância, Faria Jr. (1995) destaca a prática do futebol como um meio de ensinar aos jovens a tolerância e aceitação das diferenças individuais. Além disso, propõe procedimentos que considerem o equilíbrio das equipes por meio da divisão de habilidades motoras, modificação de regras e diversificação nas formas de escolher as equipes.

Entretanto, Altmann (1998) problematiza que tais procedimentos podem enfatizar a exclusão das meninas ao quebrar a dinâmica do jogo. A autora considera que a exclusão não acontece somente sobre o gênero, ela se manifesta para além das construções de gê- 
nero e cita a competitividade, idade, força e habilidade como outros elementos de exclusão.

Para evitar diferentes tipos de exclusão, Darido (2002) salienta que o professor precisa adequar as estratégias de ensino ligadas não só às questões de gênero, uma vez que é preciso entender a característica do contexto e propor atividades que possam unir e/ou separar os grupos, considerando os gêneros, nível de habilidade, número de alunos e outras. Procurando superar tais equívocos, Souza Júnior e Darido (2010) afirmam que o tratamento do conteúdo (futebol) na educação física escolar deve contribuir para a formação de alunos críticos e autônomos em relação à interpretação do mundo que os rodeiam.

Nesse sentido, as aulas de educação física escolar podem ser uma ferramenta favorável para ressignificar os valores sociais, desbloquear a barreira histórica e cultural sobre o futebol e contribuir para uma sociedade mais tolerante e inclusiva.

A investigação realizada possibilitou compreender os aspectos que influenciam o embate sobre o futebol entre os gêneros no contexto escolar pesquisado. Sob outra perspectiva, a configuração social e as relações de poder interligam as constatações encontradas e respaldam a interpretação dos resultados apresentados. O conceito das relações de poder perpassam pelas influências apresentadas, e possibilitam compreender que as relações de gênero podem ser transformadas em outras configurações, conforme os interesses e as articulações em que as relações sociais são construídas e cultivadas.

\section{Configuração e relações de poder: a compreensão do referencial teórico de Norbert Elias à proposta de ensino}

Apesar de Norbert Elias $(2000 ; 2008)$ não abordar de forma direta as questões relacionadas ao campo da educação, realizou-se, ao longo do estudo, uma aproximação reflexiva acerca dos conceitos de configuração e poder, vinculados às questões de gênero na prática do futebol escolar.

Para analisar as relações de gênero, utilizou-se a obra Os estabelecidos e os outsiders, a fim de compreender o conceito de configuração e subsidiar posteriores analogias em relação aos gêneros no contexto investigado. Elias e Scotson (2000, p. 8) afirmam que:

As categorias estabelecidos e outsiders se definem na relação que as nega e que as constitui como identidades sociais. Os indivíduos que fazem parte de ambas estão, ao mesmo tempo, separados e unidos por um laço tenso e desigual de interdependência. Superioridade social e moral, autopercepção e reconhecimento, pertencimento e exclusão são elementos dessa dimensão da vida social que o par estabelecidos/outsiders ilumina exemplarmente: as relações de poder.

Os autores contribuíram nos debates das relações de poder e configuração social ao analisar os grupos daquela cidade em processo de industrialização. Outras questões, como violência, discriminação e exclusão social, são características marcantes que emergiram da análise social realizada.

A organização da configuração social dá-se pela forma com que um grupo rotula negativamente ou estigmatiza o outro; assim, os autores explicam que as distintas confi- 
gurações dos agrupamentos sociais têm como elemento fundamental o desequilíbrio entre as relações de poder de um grupo sobre o outro, uma vez que a caracterização de estabelecidos e outsiders reflete a maneira como o indivíduo percebe a sua autoimagem. Dessa forma, a qualificação que o indivíduo recebe socialmente pode ser influenciada de forma positiva ou negativa, pois depende de qual grupo social ele está inserido.

Análoga aos conceitos de estabelecidos e outsiders, a prática do futebol escolar no grupo de crianças estudadas já se encontrava solidificada por quase todos os meninos. Conforme os conceitos de Elias e Scotson (2000), a maioria dos meninos passaria a ser categorizada como estabelecidos. Inversamente, a maioria das meninas, que estava à margem, passaria a ser categorizada como outsiders.

No início da mediação docente, observou-se que as meninas, quando manifestavam interesse em jogar futebol, eram rotuladas negativamente pelos meninos de ruins de bola, sapatão ou macho-fêmea ${ }^{4}$. Como explicado acima, esse comportamento era uma forma de estigmatizar e excluir as meninas, além de manter o status e o poder da prática do futebol, apenas entre os meninos.

Entretanto, observou-se que havia exceções: apenas três meninas de todo o contexto pesquisado eram aceitas pelo grupo de meninos. Ao observar a inserção dessas meninas, percebeu-se a afinidade e a habilidade que elas tinham em jogar futebol. No entanto, os estabelecidos prestigiavam-nas, e havia inclusive disputas no momento da escolha para compor as equipes.

A fim de quebrar a hegemonia dos estabelecidos, fez-se necessário, em primeiro lugar, pensar em estratégias que motivassem as(os) outsiders a praticarem futebol, pautadas na equivalência de direitos. De forma prática, utilizou-se o exemplo das meninas (estabelecidas) que já possuíam prestígio entre os estabelecidos, solicitando a elas, que incentivassem as(os) demais. Essa estratégia acabou estimulando as(os) outsiders, principalmente por se sentirem desafiadas(os). Desse momento em diante, as(os) outsiders motivaram-se em aprender a jogar futebol, e essa atitude, aos poucos, contagiou o grupo quase por completo.

Para que o planejamento obtivesse êxito, houve a necessidade de, simultaneamente, elaborar estratégias que estimulassem os estabelecidos a refletir sobre a inserção das(os) outsiders no mesmo contexto. Nessa perspectiva, procurou-se proporcionar, de forma pedagógica, a conceituação do desenvolvimento do futebol no Brasil para ambos os gêneros. Na prática, os escolares vivenciaram situações que exigiam a reflexão de valores sociais relacionados a desigualdade de direitos, divisão de espaços, divisão de materiais pedagógicos e integração entre os gêneros durante as aulas de educação física escolar.

Como estratégia de ensino para alterar as relações de poder entre os gêneros durante o desenvolvimento das aulas, utilizou-se como modelo didático o terceiro capítulo escrito por Elias (2008), "Modelos de jogo", publicado em seu livro Introdução à sociologia. O autor classifica os modelos de jogos em: competição primária sem regras; competição entre duas pessoas com regras; competição de muitas pessoas a um só nível; competição de dois níveis do tipo oligárquico; e competição de dois níveis do tipo crescente democrático.

\footnotetext{
${ }^{4}$ Termo pejorativo dado às meninas que não era correspondente com a realidade.
} 
Os modelos de competição podem ser entendidos como modelos de relações sociais, com exceção do primeiro, os outros modelos se assemelham aos jogos esportivos. Os jogos de competição permitem que as pessoas desafiem umas às outras como, por exemplo: serei eu o que chuta mais forte a gol?; seremos nós melhores que os meninos?; serás tu o que chuta mais forte?; serão eles melhores que nós? O autor considera que os jogos de competição constituem um elemento normal de todas as relações humanas. Assim, "todos os modelos se baseiam em duas ou mais pessoas que medem suas forças" (ELIAS, 2008, p. 80). Dessa maneira, a análise das relações de poder entre os gêneros baseou-se na competição (relação social) entre duas pessoas com regras.

Nesse modelo, os dois lados - estabelecidos e outsiders - possuem algum potencial de poder. Entretanto, a maioria dos meninos inicialmente possuía uma proporção maior de poder e controle do jogo sobre a maioria das meninas. De acordo com Elias (2008, p. 89), "à medida que a desigualdade de forças dos dois jogadores diminui, resultará da interpenetração de jogadas de duas pessoas individuais um processo de jogo que nenhuma delas planeou".

Elias (2008) explica que as relações de poder estão presentes em todas as relações humanas como um elemento integral. O equilíbrio de poder pode ser no mínimo bipolar, mas geralmente se apresenta de forma multipolar. $\mathrm{O}$ fato de as(os) outsiders demonstrarem interesse e motivação foi decisivo para aumentar sua força relativa e causar instabilidade, pois se elas(es) aceitassem a imposição dos estabelecidos não alterariam as relações de poder, tampouco a configuração entre os gêneros.

A mediação docente por meio da ludicidade, das atividades inclusivas e da gestão compartilhada, permitiu que as(os) outsiders participassem de jogos de futebol na mesma proporção dos estabelecidos. Posteriormente foram propostos jogos mistos e observou-se a ressignificação atitudinal entre a maioria das crianças, representadas em valores sociais como: respeito às diferenças, cooperatividade, solidariedade e reconhecimento da igualdade de direitos.

Amparados pela metáfora de Modelos de jogo de Elias (2008), afirma-se de forma análoga, que a integração dos gêneros na formação de grupos ou equipes (microssociedade) de futebol escolar foi composta por crianças (indivíduos), o que significa que a posição e as jogadas de cada jogador(a) eram dependentes do posicionamento dos(as) companheiros(as) ou dos oponentes. Por isso, as crianças, em geral, entenderam que deveriam jogar de forma cooperativa e coletiva para dar sentido ao jogo de que estavam participando.

As relações de poder perpassaram por um equilíbrio flutuante, pois a configuração de gêneros foi passível de transformações. A aproximação das crianças esteve ligada às dimensões sociais e afetivas, sendo assim, as mudanças ocorridas nas relações de gênero não estavam voltadas apenas à satisfação individual, mas principalmente associadas à satisfação dos(as) demais envolvidos(as).

Dessa maneira, a complexidade do estudo baseou-se na mediação das relações de poder entre os gêneros por intermédio do futebol, além de enfatizar os valores sociais e tornar a prática do futebol menos desigual. Não se buscou a homogeneidade entre os gêneros, pois isso seria utópico e contra as teorias dos estudos de gênero, mas sim o entendimento inicial da configuração social e das relações de poder, objetivando alterá-las sem desconsiderar a pluralidade das identidades de gêneros.

Pensar a Prática, Goiânia, v. 17, n. 4, out./dez. 2014 


\section{Proposta de ensino}

A proposta de ensino a ser apresentada, pretende compartilhar e oferecer subsídios pedagógicos para que outros professores possam utilizá-los de forma autônoma, reflexiva e significativa.

Tabela 2. Proposta de ensino: blocos didáticos

\begin{tabular}{|c|c|c|}
\hline 1ㅇ Bloco & 20 Bloco & 3- Bloco \\
\hline \multicolumn{3}{|l|}{ Atividades } \\
\hline $\begin{array}{l}\text { Pênalti, "faltinha", peteca- } \\
\text { da, cruzamento, gol a gol, } \\
\text { três toques, "bobinho"e } \\
\text { "golzinho" }\end{array}$ & $\begin{array}{c}\text { Aulas de sistematização in- } \\
\text { tercaladas com os outros } \\
\text { blocos. Vídeos sobre fute- } \\
\text { bol. Pesquisas e debates so- } \\
\text { bre preconceito e discrimi- } \\
\text { nação no futebol }\end{array}$ & $\begin{array}{l}\text { Brincadeiras e jogos com } \\
\text { bola: pega-pega, duro ou } \\
\text { mole, mãe da rua, boliche } \\
\text { com os pés, brincadeiras } \\
\text { com corda e bola, corredor, } \\
\text { bola numerada, derrube a } \\
\text { torre, artilheiro, jogos redu- } \\
\text { zidos e jogos com regras ofi- } \\
\text { ciais (minitorneio) }\end{array}$ \\
\hline \multicolumn{3}{|l|}{$\begin{array}{l}\text { Expectativas de } \\
\text { aprendizagem }\end{array}$} \\
\hline $\begin{array}{l}\text { Dar sentido/significado à } \\
\text { prática, começando com } \\
\text { atividades conhecidas e } \\
\text { propostas pelas próprias } \\
\text { crianças }\end{array}$ & $\begin{array}{l}\text { Incorporar os valores con- } \\
\text { ceituais na dimensão proce- } \\
\text { dimental e atitudinal }\end{array}$ & $\begin{array}{l}\text { Integrar e aproximar as cri- } \\
\text { anças por meio de brincadei- } \\
\text { ras populares. Entender a es- } \\
\text { trutura do jogo }\end{array}$ \\
\hline \multicolumn{3}{|l|}{ Estratégias } \\
\hline $\begin{array}{l}\text { Formação de grupos mis- } \\
\text { tos. Gestão compartilhada, } \\
\text { equivalência de direitos e } \\
\text { inclusão }\end{array}$ & $\begin{array}{c}\text { Mediação reflexiva e dialó- } \\
\text { gica }\end{array}$ & $\begin{array}{l}\text { Utilização da ludicidade, } \\
\text { globalidade e inclusão. Ges- } \\
\text { tão compartilhada }\end{array}$ \\
\hline \multicolumn{3}{|l|}{ Análise } \\
\hline $\begin{array}{c}\text { Configuração: formação } \\
\text { de grupos por gênero. Re- } \\
\text { lações de poder: imposição } \\
\text { dos meninos e rejeição das } \\
\text { meninas }\end{array}$ & $\begin{array}{l}\text { Desenvolvimento de valores } \\
\text { sociais: união, diversão, res- } \\
\text { significação da cultura fute- } \\
\text { bolística, respeito às dife- } \\
\text { renças, cooperatividade, so- } \\
\text { lidariedade, reconhecimento } \\
\text { da igualdade de direitos }\end{array}$ & $\begin{array}{c}\text { Alterações na configuração } \\
\text { e relações de poder entre os } \\
\text { gêneros. Aprendizagem da } \\
\text { estrutura do jogo e melhoria } \\
\text { das habilidades motoras de } \\
\text { forma integrada. Realização } \\
\text { de aulas mistas e coeducati- } \\
\text { vas }\end{array}$ \\
\hline
\end{tabular}

A proposta visou ultrapassar os aspectos técnicos e as formas de jogar futebol livremente. $\mathrm{O}$ desenvolvimento dos blocos didáticos, conforme recomenda Souza Júnior e 
Darido (2010), consideraram os seguintes temas: as dimensões sociais do esporte (educação, participação e rendimento); a origem do futebol (do jogo ao esporte); futebol e cultura popular (o esporte volta a ser jogo); futebol no Brasil (da elite ao povo), futebol e arte (as interfaces do futebol com as manifestações artísticas); fundamentos técnicos do futebol; futebol e ética; futebol feminino e o seu contexto; e o resgate de jogos da cultura popular. Durante o desenvolvimento da proposta, foi nítida a evolução das crianças, principalmente na descentralização do domínio de algumas crianças sobre o restante do grupo.

A próxima tabela revela essa evolução por meio da codificação dos registros das crianças em unidades textuais e aponta alterações nas relações de poder e na configuração de gêneros:

Tabela 3. Avaliação processual

\begin{tabular}{|c|c|c|c|c|}
\hline \multirow{2}{*}{ Temas } & \multicolumn{3}{|l|}{ Categori } & \multirow{2}{*}{ Unidades de codificação } \\
\hline & $\mathbf{a}$ & $\mathbf{N} *$ & $\%$ & \\
\hline \multirow{2}{*}{$\begin{array}{l}\text { Satisfação em ter parti- } \\
\text { cipado das aulas de fu- } \\
\text { tebol }\end{array}$} & Meninos & 73 & 96 & \multirow{2}{*}{$\begin{array}{l}\text { Porque: brincaram de forma mista; os meni- } \\
\text { nos ensinaram as regras e ajudaram as meni- } \\
\text { nas a melhorarem as habilidades motoras; } \\
\text { reconheceram a equivalência de direitos }\end{array}$} \\
\hline & Meninas & 69 & 83 & \\
\hline \multirow{2}{*}{$\begin{array}{l}\text { Insatisfação em ter } \\
\text { participado das aulas } \\
\text { de futebol }\end{array}$} & Meninos & 3 & 4 & \multirow{2}{*}{$\begin{array}{l}\text { Porque: é um esporte agressivo; não gostam } \\
\text { é difícil; os meninos não colaboraram }\end{array}$} \\
\hline & Meninas & 14 & 17 & \\
\hline \multirow{2}{*}{$\begin{array}{l}\text { Capacidade das meni- } \\
\text { nas de aprender futebol }\end{array}$} & Meninos & 55 & 70 & \multirow{2}{*}{$\begin{array}{c}\text { Porque: o professor e os meninos ensinaram } \\
\text { as regras; as meninas se esforçaram em } \\
\text { aprender }\end{array}$} \\
\hline & Meninas & 71 & 85 & \\
\hline \multirow{2}{*}{$\begin{array}{c}\text { Incapacidade das me- } \\
\text { ninas de aprender fute- } \\
\text { bol } \\
\end{array}$} & Meninos & 21 & 30 & \multirow{3}{*}{$\begin{array}{l}\text { Porque: as meninas não aprenderam as re- } \\
\text { gras; as meninas não têm habilidades } \\
\text { União, diversão, ressignificação da cultura } \\
\text { futebolística, respeito entre os pares, coope- } \\
\text { ração, solidariedade, equivalência de direi- } \\
\text { tos e integração entre os gêneros }\end{array}$} \\
\hline & Meninas & 12 & 15 & \\
\hline $\begin{array}{l}\text { Coeducação e valores } \\
\text { sociais }\end{array}$ & Mista & $\begin{array}{c}15 \\
9\end{array}$ & $\begin{array}{c}10 \\
0\end{array}$ & \\
\hline
\end{tabular}

- $\quad$ Número total: 76 meninos e 83 meninas

A análise do tema de satisfação indica que a maioria das crianças gostou de brincar de futebol e reconheceu a equivalência de direitos em ambos os gêneros. Além disso, as meninas reconheceram que os meninos ensinaram as regras e ajudaram a melhorar as habilidades motoras - e consequentemente a autoestima. O tema sobre a capacidade das meninas em aprender futebol aponta para a corresponsabilidade dos meninos no ensino das regras e formas de se jogar, além de as meninas demonstrarem vontade em aprender. Já as meninas reconhecem a importância dos meninos e do professor no processo de aprendizagem. Essas informações denotam a importância da ressignificação da cultura futebolística, na qual a maioria das crianças compreendeu que era possível jogar futebol de forma inclusiva, respeitosa e integrada. O tema de valores sociais e coeducação simboliza as alterações das relações de poder e da configuração entre os gêneros. 
O caminho percorrido pode ser representado pelas seguintes etapas: mediação docente por meio da equivalência de direitos e acesso/estímulo à prática do futebol, considerando como expectativas de aprendizagens a reflexão histórica e cultural do futebol unida à ressignificação dos valores sociais, ao desenvolvimento das habilidades motoras e à utilização dos conceitos de configuração e relações de poder apresentadas por Elias (2000; 2008), na compreensão das relações de gênero.

\title{
Considerações finais
}

Este estudo procurou refletir o referencial teórico de Norbert Elias $(2000 ; 2008)$ e aproximá-lo da prática pedagógica da educação física escolar. A compreensão e a reflexão de conceitos como relações de poder e configuração possibilitaram modificar as estruturas de pensamento hegemônicas no que se refere à apropriação do futebol relacionadas às questões de gênero, e permitiram analisar o mundo social por intermédio de uma consistente ferramenta metodológica na compreensão das relações humanas.

Inicialmente as meninas demonstraram pouco interesse em participar de aulas relacionadas ao tema futebol, o que pode ser explicado pela influência histórica e cultural refletida no desequilíbrio das relações de poder, uma vez que a maioria dos meninos configurava-se como estabelecidos. Nesse contexto, a falta de estímulo à prática e o baixo desenvolvimento das habilidades motoras também foram decisivas para configurar a maioria das meninas como outsiders.

A utilização do futebol como conteúdo e estratégia de ensino proporcionou alterações positivas nas relações de poder e na configuração social (estabelecidos/outsiders) entre os gêneros, além de atingir satisfatoriamente as expectativas de aprendizagens elencadas. A mediação docente, aliada à proposta de ensino, revelou-se inerente à reflexão da cultura futebolística e à ressignificação e/ou formação de valores sociais, como a inclusão, o respeito, a cooperação e a equivalência de direitos.

Conclui-se que as reflexões de conceitos como configuração e relações de poder utilizadas na proposta de ensino possibilitaram evidenciar alterações profícuas nas relações de gênero.

PHISYCAL EDUCATION, SOCCER AND GENDER: A TEACHING PROPOSAL FROM THE POWER RELATIONS

\begin{abstract}
This study aimed to observe the social configuration and power relations between genders from the experimentation and evaluation of soccer a proposal of teaching, in $4^{\text {th }}$ and $5^{\text {th }}$ grades of elementary school in Brazil, based on the theoretical framework of Norbert Elias. It was used action research and the technique of content analysis as methodological procedures for the analysis of information. Results revealed that the non interest about soccer is associated with the lack of mo tor skills and historical and cultural aspects. It was concluded that the reflexive use of concepts, such as configuration and power relations, related to the proposed learning enabled fruitful changes in the gender relations.
\end{abstract}

Keywords: Gender relations. Social values. Soccer.

Pensar a Prática, Goiânia, v. 17, n. 4, out./dez. 2014 


\title{
EDUCACIÓN FÍSICA, FÚTBOL Y GÉNERO: UNA PROPUESTA DE ENSEÑANZA DE LAS RELACIONES DE PODER
}

\begin{abstract}
Resumen
Este estudio pretende observar la configuración social y las relaciones de poder entre los géneros de la experimentación y evaluación del fútbol como una propuesta de enseñanza, en las clases de los 4ㅇ y 5ํaños de escuela primaria, basado en el marco teórico de Norbert Elias. Se utilizó la pesquisa-acción y la técnica de análisis de contenido como procedimientos metodológicos para analizar la información. Los resultados revelaron que la falta de interés por el fútbol se asocia con la falta de habilidades motoras, aspectos históricos y culturales. Se concluye que las reflexiones de conceptos tales como la configuración y las relaciones de poder en la propuesta de enseñanza, ha permitido demostrar cambios positivos en las relaciones de género.
\end{abstract}

Palabras-claves: Relaciones de género. Valores sociales. Fútbol.

\section{Referências}

ABREU, N. G. Meninos pra cá, meninas pra lá? In: VOTRE, S. J. (Org.). Ensino e avaliação em educação física. São Paulo: Ibrasa, 1992. p. 101-120.

ALTMANN, H. Rompendo fronteiras de gênero: Marias (e) homens na educação física. 1998. 108 f. Dissertação (Mestrado em Educação) - Universidade Federal de Minas Gerais, Belo Horizonte, 1998.

ALTMANN, H. Exclusão nos esportes sob um enfoque de gênero. Motus Corporis, Rio de Janeiro, v. 9, n. 1, p. 9-20, 2002.

ANDRADE, E. B.; DEVIDE, F. P. Auto-exclusão nas aulas de educação física escolar: representações de alunas do Ensino Médio sob enfoque de gênero. Fiep Bulletin, Foz do Iguaçu, v. 76, p. 318-322, 2006.

ANDRÉ, M. E. D. A. Etnografia da prática escolar. Campinas, SP: Papirus, 1995.

BARDIN, L. Análise de conteúdo. Lisboa: Edições 70, 1977.

BETTI, M. "Imagens em ação": uma pesquisa-ação sobre o uso de matérias televisivas em programas de educação física do ensino fundamental e médio. Movimento, Porto Alegre, v. 12, n. 2, p. 95-120, maio/ago. 2006.

BRACHT, V. et al. A prática pedagógica em educação física: a mudança a partir da pesquisa-ação. Revista Brasileira de Ciências do Esporte, Campinas, v. 23, n. 2, p. 9-29, jan. 2002.

BRASIL. Ministério da Educação. Secretaria de Educação Fundamental. Parâmetros curriculares nacionais: Educação Física. Brasília: MEC/SEF, 1998. 
BUTLER, J. Atos corporais subversivos. In: . Problemas de gênero: feminismo e subversão da identidade. Rio de Janeiro: Civilização Brasileira, 2003.

DARIDO, S. C. Futebol feminino no Brasil: do seu início à prática pedagógica. Motriz, Rio Claro, v. 8, n. 2, p. 43-49, dez. 2002.

DEVIDE, F. P. et al. Produção de sentidos sobre a visibilidade de mulheres atletas no jornalismo esportivo: interpretações a partir do Caderno de Esportes do jornal "O Globo". In: ROMERO, E.; PEREIRA, E. G. (Org.). Universo do corpo: masculinidades e feminilidades. Rio de Janeiro: Shape/Faperj, 2008. p. 400-416.

DEVIDE, F. P. et al. Estudos de gênero na educação física brasileira. Motriz, Rio Claro, v. 17, n. 1, p. 93-103, jan./mar. 2011.

ELIAS, N.; SCOTSON, J. L. Os estabelecidos e os outsiders: sociologia das relações de poder a partir de uma pequena comunidade. Tradução de Vera Ribeiro. Rio de Janeiro: Jorge Zahar, 2000.

ELIAS, N. Modelos de jogo. In: Introdução à sociologia. Tradução de Maria Luísa Ribeiro Ferreira. São Paulo: Martins Fontes, 2008. p. 77-112.

ELLIOT. J. La investigación-acción en educación. Madrid: Morata, 1990.

ELLIOT. J. El cambio educativo desde la investigación-acción. Madrid: Morata, 1993.

FARIA JR., A. G. Futebol, questões de gênero e coeducação: algumas considerações didáticas sob enfoque multicultural. Pesquisa de Campo: Futebol e Cultura Brasileira, Rio de Janeiro, n. 2, p. 17-39, dez. 1995.

GOELLNER, S. V. Bela, feminina e maternal: imagens da mulher na Revista Educação Physica. Ijuí: Unijuí, 2003.

GOELLNER, S. V. Mulher e esporte no Brasil: fragmento de uma história generificada. In: SIMÕES, A. C.; KNIJNIK, J. D. O mundo psicossocial da mulher no esporte: comportamento, gênero, desempenho. São Paulo: Aleph, 2004. p. 359-373.

GOELLNER, S. V. Mulheres e futebol no Brasil: entre sombras e visibilidades. Revista Brasileira de Educação Física e Esporte, São Paulo, v. 19, n. 2, p. 143-151, abr.jun. 2005.

GOMES, P. B.; SILVA, P.; QUEIRÓS, P. Distintos registros sobre o corpo feminino: beleza, desporto e mídia. In: ROMERO, E.; PEREIRA, E. G. B. (Org.). Universo do Corpo: masculinidades e feminilidades. Rio de Janeiro: SHAPE/FAPERJ, 2008, p. 387-400.

KNIJNIK. J. D.; SOUZA, J. S. S. de. Diferentes e desiguais: relações de gênero na mídia esportiva brasileira. In: SIMÕES, A. C.; KNIJNIK, J. D. (Org.). O mundo psicossocial 
da mulher no esporte: comportamento, gênero e desempenho. São Paulo: Aleph, 2004. p. 191-212.

LOURO, G. Gênero, sexualidade e educação: uma perspectiva pós-estruturalista. Rio de Janeiro; Petrópolis: Vozes, 1997.

LOURO, G. Um corpo estranho: ensaios sobre sexualidade e teoria queer. Belo Horizonte: Autêntica, 2004.

LUZ JÚNIOR, A. Educação física e gênero: olhares em cena. São Luís: Imprensa UFMA/Corsup, 2003.

PEREIRA, E. G. B. Discutindo gênero, corpo e masculinidade. In: ROMERO, E.; PEREIRA, E. G. (Org.). Universo do corpo: masculinidades e feminilidades. Rio de Janeiro: Shape/Faperj, 2008. p. 87-101.

ROMERO, E. A (in)visibilidade da mulher atleta no jornalismo esportivo do Rio de Janeiro. In: SIMÕES, A. C.; KNIJNIK, J. D. (Org.). O mundo psicossocial da mulher no esporte: comportamento, gênero e desempenho. São Paulo: Aleph, 2004. p. 213-252.

ROMERO, E. Construção e reprodução da masculinidade e da feminilidade no esporte pela mídia escrita. In: ROMERO, E.; PEREIRA, E. G. (Org.). Universo do corpo: masculinidades e feminilidades. Rio de Janeiro: SHAPE/FAPERJ, 2008. p. 333-383.

SARAIVA, M. C. Co-educação física e esportes: quando a diferença é mito. Ijuí: Unijuí, 1999.

SAYÃO, D. T. A construção de identidades e papéis de gênero na infância: articulando temas para pensar o trabalho pedagógico da Educação Física na educação infantil. Revista Pensar a Prática, Goiânia, v. 5, p. 1-14, 2001-2002.

SCOTT, J. Gênero: uma categoria útil de análise. Educação \& Realidade, Porto Alegre, v. 20, n. 2, p. 71-100, jul./dez. 1995.

SOUSA, E. S; ALTMANN, H. Meninos e meninas: expectativas corporais e implicações na educação física escolar. Cadernos CEDES, Campinas, ano 19, n. 48, p. 52-68, ago. 1999.

SOUZA JÚNIOR, O. M.; DARIDO, S. C. Influências da cultura escolar no desenvolvimento de propostas co-educativas em aulas de Educação Física. Motriz, Rio Claro, v. 9, n. 3, p. 143-151, set./dez. 2003.

SOUZA JÚNIOR, O. M.; DARIDO, S. C. Refletindo sobre a tematização do futebol na Educação Física escolar. Motriz, Rio Claro, v. 16, n. 4, p. 920-930, out./dez. 2010. 
STENHOUSE, L. An introduction to curriculum research and development. Londres: Heinemann, 1975.

THIOLLENT, M. Metodologia da pesquisa-ação. São Paulo: Cortez, 1986.

Recebido em: 06/07/2014

Revisado em: 18/07/2014

Aprovado em:28/07/2014

Endereço para correspondência:

hudsonfpnunes@hotmail.com

Hudson Fabricius Peres Nunes

Universidade Estadual Paulista Rua Quirino de Andrade, 215

01049-010 - São Paulo, SP

Pensar a Prática, Goiânia, v. 17, n. 4, out./dez. 2014 